\title{
THE NEW GENERALIZED GRAVITATIONAL MODEL OF MIGRATION FOR GEORGIA
}

\section{QETEVAN PIPIA}

PhD student of Samtskhe-Javakheti

State University, Georgia

qetino.pipia@gmail.com

\section{GOCHA TUTBERIDZE}

Doctor of Economics, Professor

European University, Georgia

gtutberidze@esu.edu.ge

\section{GIVI RAKVIASHVILI}

Doctor of Mathematics,

Associate Professor, Ilia State University, Georgia

giorgi.rakviashvili@iliauni.edu.ge

\section{KRISTINE RAKVIASHVILI}

Researcher, Union of Young

Olympic Mathematicians, Georgia

qrakviashvili@gmail.com

Abstract. Econophysics, or the theory of construction of models using physical assumptions in economics, already has a long history. For this purpose, the gravitational law of attraction was probably first used in the modeling of trade models between two subjects. The laws of gravitational and electrostatic attraction were then used to study migration between countries. The article adopts two new models (containing dummy variables) of migration from Georgia to leading European countries and USA using multivariate linear regression. They are based on the Lewer and van der Berg generalized gravitational model of migration between countries of The Organisation for Economic Co-operation and Development (OECD). Their model contains dummy parameters of border, the proximity of the state languages and colonial links in past. In this article we introduce a new dummy parameter «religion» of the model of migration from Georgia; It is hypothesized that migration between neighbor countries may not be analogous to the Newton s law of universal gravitation. In our view, it would be more appropriate to use other physical assumptions to construct such a migration model, for example a mathematical model of the law of equalization of temperatures in an area with different temperatures at different points.

\section{KEYWORDS: ECONOPHYSICS, MIGRATION, GRAVITATIONAL ATTRACTION LAW, ELECTROSTATIC ATTRACTION LAW,} DUMMY PARAMETERS

For citation: Pipia, Q., Tutberidze, G., Rakviashvili, G., Rakviashvili, K. (2020). The New Generalized Gravitation Model of Migration for Georgia. Globalization and Business, 10. 130-137. https://doi.org/10.35945/gb.2020.10.016

Econophysics, or the theory of construction of models using physical assumptions in economics, already has a long history [1]. For this purpose, the gravitational law of attraction was probably first used in the modeling of trade models between two subjects [2-3]. The laws of gravitational and electrostatic attraction were then used to study migration between countries [45]. For example, the electrostatic migration model discussed in [4] is

$$
M_{i j}=k \frac{q_{i} \rho_{j}}{\varepsilon} \frac{a^{2}}{R^{2}},(1)
$$


where $M_{i j}$ is a number of migrants from poor $i$ country to rich $j$ country, $q_{i}$ is the population of a poor country, $\rho_{j}$ is the population of a rich country, $a$ is the size (radius) of a rich region, $R$ is the distance between these countries, $k$ is a coefficient of proportionality, $\varepsilon$ is a "penetration" of the rich country, i.e. a different barriers.

Let us consider the possibility of applying the migration model proposed in [6] for Georgia. This model calculates the natural logarithm of the number of migrants from a $i$ country to a $j$ country

$$
\begin{aligned}
& \ln \left(M_{i j}\right)=a_{0}+a_{1} \ln \left(\text { pop }_{i} \cdot \text { pop }_{j}\right)+a_{2} \ln \left(\text { dist }_{i j}\right)+a_{3}\left(\text { rely }_{i j}\right)+ \\
& +a_{4} \ln \left(\text { stock }_{i j}\right)+a_{5} \text { CONT }_{i j}+a_{6} L A N G_{i j}++a_{7} L I N K_{i j}+u_{i j}
\end{aligned}
$$

where $M_{i j}$ is a number of migrants from poor $i$ country to rich $j$ country;

pop $_{i} \cdot$ pop $_{j}$ is the product of the population of the respective countries;

dist $_{i j}$ is the distance between countries;

rely $y_{i j}$ is the ratio of the per capita income of the country $j$ to the per capita income of the country $i$;

stock $k_{i j}$ is the number of people already emigrating from country $i$ to country $j$ (the larger the already emigrated population is, the easier it is to migrate and adapt;

$C O N T_{i j}$ is a dummy parameter of the common border between these two countries;

$L A N G_{i j}$ is a dummy parameter of the proximity of the state languages of these two countries;

$L I N K_{i j}$ is a dummy parameter of colonial links in past between these two countries;

$u_{i j}$ is the error function.

Let us note that the value of the dummy parameter is 1 or 0 , depending on whether the condition is fulfilled or not; For example, if the source country was a colony of the destination country, the dummy parameter is equal to 1 , otherwise it is equal to 0. In the model under consideration, $C O N T_{i j}, L A N G_{i j}$ and $L I N K_{i j}$ are dummy parameters.

In this model it is expected that $a_{2}$ is negative.

In the article [6] the coefficients from (2) estimates based on migration data between countries of The Organisation for Economic Co-operation and Development (OECD); This organization includes the following 25 countries: Australia, Austria, New Zealand, Belgium, United Kingdom, Germany, Canada, Denmark, Spain, Turkey, Japan, Ireland, Iceland, Italy, Luxembourg, Netherlands, Norway, Portugal, Greece, France, Finland, United States, Switzerland, Sweden. According to [6], these coefficients are:

$$
a_{0}=4.218, a_{1}=0.221, a_{2}=-0.261, a_{3}=0.00004, a_{4}=0.401, a_{5}=-0.091, a_{6}=0.275, a_{7}=0.288 .
$$

Therefore (2) formula will take the following form:

$$
\begin{aligned}
& \ln \left(M_{i j}\right)=4.218+0.221 \cdot \ln \left(\text { pop }_{i} \cdot \text { pop }_{j}\right)- \\
& \quad-0.261 \cdot \ln \left(\text { dist }_{i j}\right)+0.00004 \cdot\left(\text { rely }_{i j}\right)+(3) \\
& \quad+0.401 \cdot \ln \left(\text { stock }_{i j}\right)+0.275 \cdot \text { Lang }_{i j}- \\
& \quad-0.091 \cdot \text { CONT }_{i j}+0.288 \cdot \text { LINK }_{i j}+u_{i j} .
\end{aligned}
$$

We are using (3) formula to study migration from Georgia. According to the World Bank [7], there were 4,9000,000 people living in Georgia in 1995; This period is relevant for our purposes, because at that time the Russian-speaking population had left Georgia. The population of the countries of our interest, and the distance between Tbilisi and the capitals of these countries, can be found on the Internet. The World Bank tables [8], which give the GDP per capita from 1960-2017, can be used to determine the GDP per capita by countries. 
Table 1. Official Statistics on Migration from Georgia (in thousands) - [9]

\begin{tabular}{|c|c|c|c|c|c|c|c|c|c|c|c|c|}
\hline 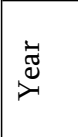 & $\underset{\Xi}{\Xi}$ & 筩 & 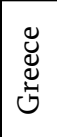 & 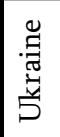 & 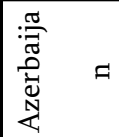 & 密 & 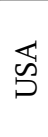 & 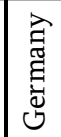 & 岕 & 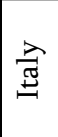 & $\begin{array}{ll}\vec{\Xi} & \tilde{\Xi} \\
\tilde{\varpi} & \text { की }\end{array}$ & 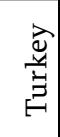 \\
\hline 2017 & 840 & 450 & 80 & 70 & 50 & 40 & 30 & 20 & 20 & 10 & 1 to 10 & \\
\hline 2000 & 910 & 630 & 70 & 70 & 60 & 50 & 10 & & & & 20 & \\
\hline 1990 & 880 & 660 & & 80 & 70 & 40 & & & & & 30 & \\
\hline
\end{tabular}

To evaluate the results of the formula (3), we need to know the number of emigrants from Georgia to different countries. Unfortunately, the official data and the unofficial statistical data of the Office of the State Minister of Georgia for Diaspora Issues differ significantly (see Tables 1 and 2).

Table 2. Unofficial statistics of the Ministry of Diaspora - 2015;

The total number of emigrants is approx. 1,600 thousands in 42 countries [9-10].

\begin{tabular}{|c|c|c|c|c|c|c|c|}
\hline Russia & 800000 & Italy & 12124 & Switzerlan & 2000 & Moldova & 500 \\
\hline Greece & 250000 & Israel & 10000 & Armeny & 1000 & Romania & 500 \\
\hline Ukraine & 150000 & Autriche & 10000 & Bulgaria & 1000 & Slovakia & 500 \\
\hline Turkey & 100000 & Kazakhstan & 7000 & Czechia & 1000 & Estonia & 500 \\
\hline USA & 80000 & Cyprus & 7000 & Hungary & 1000 & Lithuania & 500 \\
\hline Azerbaijan & 35000 & Belarus & 5000 & Finland & 1000 & Lietuva & 300 \\
\hline Spain & 30000 & Nederlands & 5000 & Norway & 1000 & Kyrgyzstan & 200 \\
\hline Germany & 25000 & Uzbekistan & 4000 & Danmark & 1000 & Japan & 100 \\
\hline Belgium & 20000 & Portugal & 3000 & Irland & 1000 & Australia & 20 \\
\hline France & 20000 & Sweden & 3000 & Canada & 1000 & & \\
\hline UK & 15000 & Poland & 2000 & Tajikistan & 500 & & \\
\hline
\end{tabular}

Table 3. Migration from Georgia with 1995 data and amended by $\mathrm{a}_{4}$ and stock.

P.R.C. - Research Center; Diasp. - Unofficial data of the Ministry of Diaspora

\begin{tabular}{|c|c|c|c|c|c|c|c|c|c|c|c|c|c|}
\hline & \multicolumn{2}{|c|}{$\begin{array}{c}\text { Migrants } \\
\text { (thous.) }\end{array}$} & \multirow{2}{*}{$\begin{array}{c}\text { pop } \\
\text { (mill.) }\end{array}$} & \multirow{2}{*}{$\begin{array}{l}\text { dist } \\
(\mathrm{km})\end{array}$} & \multirow[b]{2}{*}{ GDP PPP } & \multirow[b]{2}{*}{ rel } & \multirow{2}{*}{$\begin{array}{c}\text { Compatri } \\
\text { ots }\end{array}$} & \multirow[b]{2}{*}{ a3 } & \multirow[b]{2}{*}{ Lang } & \multirow[b]{2}{*}{ cont } & \multirow[b]{2}{*}{ Link } & \multirow[b]{2}{*}{$\ln (\mathrm{Mij})$} & \multirow[b]{2}{*}{ Mij } \\
\hline & P.R.C. & Diasp. & & & & & & & & & & & \\
\hline Sum & 840 & 1608 & 4.9 & & 1,884 & & & & & & & & \\
\hline Georgia & 0 & 0 & 4.9 & 0 & 1,884 & & & & & & & & \\
\hline Russia & 450 & 800 & 160 & 1648 & 5613 & 3.30 & 100000 & 0.00004 & 1 & 1 & 1 & 14.9528 & 3118289 \\
\hline Russia & 450 & 800 & 160 & 1648 & 5613 & 3.30 & 100000 & 0.04 & 1 & 1 & 1 & 15.0845 & 3557260 \\
\hline Russia & 450 & 800 & 160 & 1648 & 5613 & 3.30 & 100000 & 0.004 & 1 & 1 & 1 & 14.96585 & 3159256 \\
\hline Russia & 450 & 800 & 160 & 1648 & 5613 & 3.30 & 100000 & 0.00004 & 0 & 1 & 0 & 14.3898 & 1775859 \\
\hline Russia & 450 & 800 & 160 & 1648 & 5613 & 3.30 & 14000 & 0.00004 & 0 & 1 & 0 & 13.60138 & 807246 \\
\hline USA & 30 & 80 & 329 & 9300 & 28691 & 16.85 & 10 & 0.00004 & 0 & 0 & 0 & 10.49566 & 36158 \\
\hline Greec & 80 & 150 & 10.8 & 1845 & 15,404 & 9.05 & 1000 & 0.00004 & 0 & 0 & 0 & 12.00947 & 164304 \\
\hline Turkey & 8 & 100 & 80.8 & 1024 & 10,383 & 4.40 & 100 & 0.00004 & 0 & 1 & 0 & 11.59307 & 108344 \\
\hline Ukraine & 70 & 150 & 42.5 & 1467 & 3,987 & 2.18 & 500 & 0.00004 & 0 & 0 & 0 & 12.09374 & 178749 \\
\hline Azerb. & 50 & 35 & 10 & 448 & 2511 & 1.47 & 80 & 0.00004 & 0 & 1 & 0 & 11.25745 & 77455 \\
\hline Armen. & 40 & & 3 & 170 & 1592 & 0.93 & 30 & 0.00004 & 0 & 1 & 0 & 10.85234 & 51655 \\
\hline Germany & 20 & 25 & 80 & 2641 & 23,521 & 13.85 & 2 & 0.00004 & 0 & 0 & 0 & 9.866214 & 19268 \\
\hline Cyprus & 20 & & 0.5 & 2629 & 17,065 & 10.02 & 100 & 0.00004 & 0 & 0 & 0 & 10.31436 & 30163 \\
\hline Italy & 10 & & 59.6 & 2669 & 22,353 & 13.09 & 20 & 0.00004 & 0 & 0 & 0 & 10.7216 & 45325 \\
\hline Spain & & 30 & 46.7 & 4025 & 16,258 & 9.52 & 100 & 0.00004 & 0 & 0 & 0 & 11.20583 & 73558 \\
\hline
\end{tabular}


Table 4. Migration from Georgia with 1995 data and amended by $\mathrm{a}_{4}$ and stock.

P.R.C. - Research Center; Diasp. - Unofficial data of the Ministry of Diaspora (continuation of Table 3).

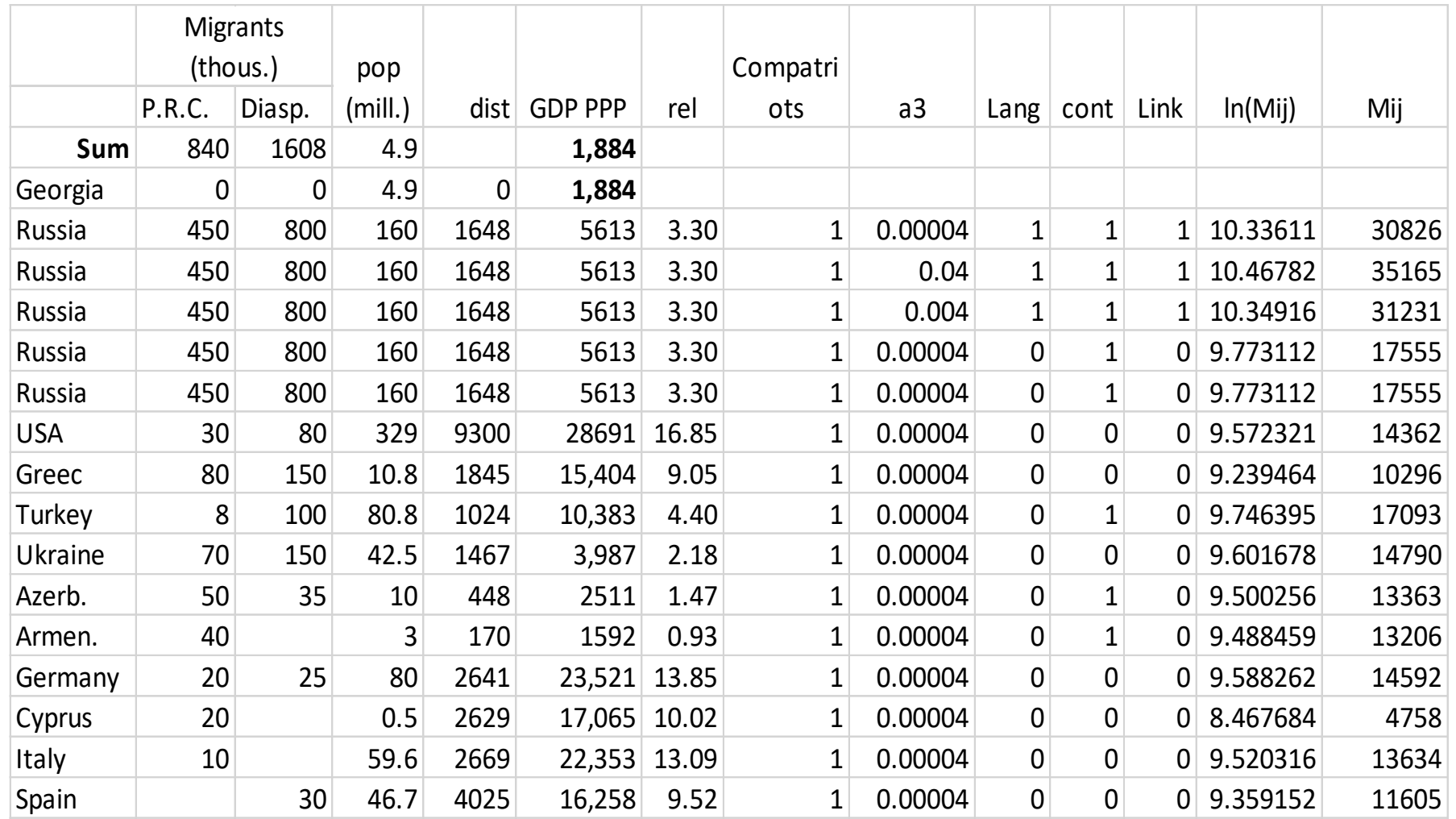

Based on Formula (3) and using the above databases, we can now evaluate the effectiveness of Formula (3) to describe emigration from Georgia (see Tables 3 and 4); All you have to do is use the appropriate tools in Ms Excel.

According to a study by the Pew Research Center, one of the most competent organizations in the United States, 450,000 people migrated from Georgia to Russia in 1995-2015, while according to unofficial data from the Ministry of Diaspora, this number is almost twice greater and is equal to 800,000 (Table 4). The situation is similar when determining the number of migrants in other countries; We can consider the example of the United States, where 30 thousand people migrated according to the data of the US Research Center, while the data of the Ministry of Diaspora is equal to 80 thousand migrants. Accordingly, these data were 80 thousand and 150 thousand for Greece ( 250 thousand people left Georgia for Greece, but 100 thousand of them were ethnic Greeks), and for Ukraine 70 thousand and 150 thousand. The total number of migrants, according to the Pew Research Center, were 840 thousand people, while according to unofficial data from the Ministry of Diaspora, this number is almost 2 times greater than the data of the Pew Research Center and is equal to 1607 thousand people. In our opinion, the data of the Ministry of Diaspora is more in line with reality, which is confirmed by the results of the general population census. From these data we can conclude that it is very attractive, affordable and easy for the population of Georgia to migrate and adapt to Russia, Greece, Ukraine and the United States.

In Table 3 and Table 4, we calculate the number of emigrants from Georgia according to the gravitational model of [6]. Data that affect the magnitude of migration are considered. These are: population, distance between capitals, ratio of GDP per capita to GDP, number of people already emigrating from country to country, dummy parameter of common border between two countries; A dummy parameter of the proximity of the state languages of the two countries; The dummy parameter of the colonial link between the two countries.

Analyzing the emigration from Georgia, we can conclude from Table 4 that although some parameters have varied, namely the number of compatriots already residing in the host countries (column 7), the coefficient of rel $_{i j}$ (column 8 ) and dummy parameters, 3 and 4 tables show that (6) model does not adequately reflect the number of emigrants from Georgia to different countries.

So, we decided to recalculate the coefficients of (6) model using linear regression of multiple variables containing dummy parameters, using the appropriate tools in MS Excel; At the same time, we added a new dummy parameter - "Relig", which takes the value of 1 when countries have a common religion, otherwise it is equal to 0 . Also, we removed the dummy parameter 
of the existence of a common language, because Georgia has no common language with any of the countries listed below. We considered that, although at some point almost all Georgian citizens knew at least a little Russian, there was no reason to consider Russian as a common language of Russia and Georgia (unlike Tables 3 and 4). At the same time, the list of countries, in which migration was studied, was expanded, although Armenia and Azerbaijan were excluded, as migration was clearly ethnic in nature.

Table 5. 1995 data from World Bank statistics [8].

\begin{tabular}{|c|c|c|c|c|c|c|c|c|c|c|c|c|c|c|}
\hline 1,995 & Diasp & POP & dist & GDP PPP & Compatr & & & & & & & & & \\
\hline Georgia & & $4,900,000$ & & 1,884 & STOCK & $\ln ($ Diasp) & $\begin{array}{r}\text { In(POPi. } \\
\text { POPj) }\end{array}$ & Ln(dist) & rel & $\ln (\mathrm{STOCK})$ & cont & Link & Relig & $\ln (\mathrm{Mij})$ \\
\hline Russia & 800,000 & $160,000,000$ & 1,648 & 5,613 & 100,000 & 13.592 & 34.295 & 7.407 & 2.979 & 11.513 & 1 & 1 & 1 & 13.647 \\
\hline USA & 80,000 & $329,000,000$ & 9,300 & 28,691 & 1,000 & $11.290^{\prime}$ & 35.016 & 9.138 & 15.229 & 6.908 & 0 & 0 & 0 & 11.004 \\
\hline Greece & 150,000 & $10,816,000$ & 1,845 & 15,404 & 3,000 & $11.918^{\prime}$ & 31.601 & $7.520^{\prime}$ & 8.176 & 8.006 & 0 & 0 & 1 & 11.214 \\
\hline Turkey & 100,000 & $80,811,000$ & 1,024 & 10,383 & 1,500 & $11.513^{\prime}$ & 33.612 & 6.931 & 5.511 & 7.313 & 1 & 1 & 0 & 11.459 \\
\hline Ukraine & 150,000 & $42,542,000$ & 1,467 & 3,987 & 10,000 & $11.918^{\prime}$ & 32.971 & $7.291^{\prime}$ & 2.116 & 9.210 & 0 & 0 & 1 & 12.077 \\
\hline Germany & 25,000 & $80,000,000$ & 2,641 & 23,521 & 1,000 & $10.127^{\prime}$ & 33.602 & $7.879^{\prime}$ & 12.485 & 6.908 & 0 & 0 & 0 & 10.233 \\
\hline Cyprus & 7,000 & 500,000 & 2,629 & 17,065 & 500 & $8.854^{\prime}$ & 28.527 & 7.874 & 9.058 & 6.215 & 0 & 0 & 1 & 9.345 \\
\hline Italy & 12,000 & $59,571,000$ & 2,669 & 22,353 & 1,000 & $9.393^{\prime}$ & 33.307 & 7.889 & 11.865 & 6.908 & 0 & 0 & 0 & 10.040 \\
\hline Spain & 30,000 & $46,700,000$ & 4,025 & 16,258 & 1,000 & $10.309^{\prime}$ & 33.064 & $8.300^{\prime}$ & 8.630 & 6.908 & 0 & 0 & 0 & 9.874 \\
\hline Belgium & 20,000 & $11,200,000$ & 3,229 & 22,405 & 300 & $9.903^{\prime}$ & 31.636 & $8.080^{\prime}$ & 11.892 & 5.704 & 0 & 0 & 0 & 9.069 \\
\hline France & 20,000 & $66,700,000$ & 3,372 & 20,740 & 1,500 & $9.903^{\prime}$ & 33.420 & 8.123 & 11.008 & 7.313 & 0 & 0 & 0 & 10.038 \\
\hline UK & 15,000 & $64,100,000$ & 3,542 & 20,516 & 1,000 & $9.616^{\prime}$ & 33.381 & 8.172 & 10.890 & 6.908 & 0 & 0 & 0 & 10.071 \\
\hline Austria & 10,000 & $8,500,000$ & 2,339 & 23654 & 400 & $9.210^{\prime}$ & 31.360 & 7.757 & 12.555 & 5.991 & 0 & 0 & 0 & 8.863 \\
\hline Netherlands & 5,000 & $17,419,000$ & 3,203 & 23403 & 300 & $8.517^{\prime}$ & 32.078 & 8.072 & 12.422 & 5.704 & 0 & 0 & 0 & 9.363 \\
\hline Israel & 10,000 & $9,241,000$ & 1,396 & 19,892 & 500 & $9.210^{\prime}$ & 31.444 & 7.241 & 10.558 & 6.215 & 0 & 0 & 0 & 8.977 \\
\hline All & 1607744 & & & & & & & & & & & & & 155.274 \\
\hline
\end{tabular}

The data in Table 5, as noted, belong to 1995. Its first column is the list of countries, the second column (Diasp) is according to unofficial data of the Ministry of Diaspora the number of Georgian emigrants in these countries, the column ends with the total number of emigrants 1607744 . The third column is the population in the respective countries, the fourth column is the distance from Tbilisi to the capitals of the respective countries, the fifth column is the gross domestic product of the respective countries, the sixth column is the number of compatriots before migrating to the respective countries, the seventh column is the logarithms of the second column data with natural base, the eighth column consists of natural logarithms of the population of Georgia and the respective country, the tenth column consists of the ratio of the GDP of the respective country and the GDP of Georgia, the eleventh column consists of the natural logarithms of the sixth column (number of compatriots before migration), the twelfth column is the dummy parameter of the common border, the thirteenth column is the colonial link in past dummy parameter, the fourteenth column is a parameter of the common religion, the fifteenth column consists of the approximate numbers of emigrants in the respective countries, calculated by the formula (4) obtained by using multivariate regression instrument of MS Excel.

The data in Table 5, using MS Excel's Data>Regression function, gives us the corresponding values of the coefficients of gravitational model of migration at $95 \%$ confidence interval, given in Table 6 . The column in this table, called Coefficients, gives us a model of migration from Georgia obtained by regression:

$$
\begin{aligned}
\ln \left(M_{i j}\right)=-10.458+0.683 \ln \left(P_{O} O P_{i} . P O P_{j}\right)-0.121 \ln (\text { dist })-0.015 \text { rel }- \\
0.160 \ln (\text { STOCK })+1.061 \text { Link }+2.413 \text { Relig. (4) }
\end{aligned}
$$

The coefficient with "cont" is zero because the columns "cont" and "Link" coincide. The last column of Table 5 shows the number of people emigrating from Georgia to the respective countries, which is calculated by formula (4). Comparison of the obtained values with the data of the Ministry of Diaspora shows the advantage of formula (4). 
Table 6

\begin{tabular}{|c|c|c|c|c|c|c|c|c|}
\hline \multicolumn{9}{|l|}{ SUMMARY OUTPUT } \\
\hline \multicolumn{9}{|c|}{ Regression Statistics } \\
\hline Multiple R & 0.939027 & & & & & & & \\
\hline R Square & 0.881772 & & & & & & & \\
\hline Adjusted R Square & 0.668101 & & & & & & & \\
\hline Standard Error & 0.640622 & & & & & & & \\
\hline Observations & 15 & & & & & & & \\
\hline \multirow{2}{*}{\multicolumn{9}{|c|}{ ANOVA }} \\
\hline & & & & & & & & \\
\hline & $d f$ & SS & MS & $F$ & Significance $F$ & & & \\
\hline Regression & 7 & 24.48672 & 3.498103 & 9.944332 & 0.003574038 & & & \\
\hline Residual & 8 & 3.283173 & 0.410397 & & & & & \\
\hline \multirow[t]{2}{*}{ Total } & 15 & 27.7699 & & & & & & \\
\hline & \multicolumn{3}{|c|}{ Coefficien Standard Et Stat } & P-value & Lower $95 \%$ & Upper 95\% & Lower $95.0 \%$ & Upper 95.0\% \\
\hline Intercept & -10.4584 & 6.550357 & -1.59662 & 0.149018 & -25.56355608 & 4.64674276 & -25.56355608 & 4.646742762 \\
\hline $\ln ($ POPi.POPj) & 0.682748 & 0.308773 & 2.211169 & 0.057975 & -0.029282399 & 1.39477914 & -0.029282399 & 1.39477914 \\
\hline $\operatorname{Ln}($ dist $)$ & -0.12078 & 0.581428 & -0.20772 & 0.840636 & -1.461551184 & 1.21999936 & -1.461551184 & 1.219999361 \\
\hline rel & -0.01543 & 0.11416 & -0.13517 & 0.895813 & -0.278685571 & 0.2478225 & -0.278685571 & 0.247822505 \\
\hline $\ln (\mathrm{STOCK})$ & -0.1601 & 0.440778 & -0.36322 & 0.725852 & -1.176534271 & 0.85633711 & -1.176534271 & 0.856337113 \\
\hline cont & 0 & 0 & 65535 & \#NUM! & 0 & 0 & 0 & 0 \\
\hline Link & 1.061203 & 0.74545 & 1.423574 & \#NUM! & -0.65780764 & 2.7802138 & -0.65780764 & 2.7802138 \\
\hline Relig & 2.4126 & 1.190618 & 2.026343 & 0.077294 & -0.3329697 & 5.15817033 & -0.3329697 & 5.158170328 \\
\hline
\end{tabular}

As we can see, the coefficient with "rel" and "In (STOCK)" is negative, i.e. more income and a common border do not promote migration, but vice versa. We think the reason for this is that migration between neighbor countries may not be described by the law of gravitational attraction because determining the distance between these countries as the

Table 7

\begin{tabular}{|c|c|c|c|c|c|c|c|c|c|c|}
\hline 1,995 & Diasp & POP & dist & GDP PPP & & & & & & \\
\hline Georgia & & $4,900,000$ & & 1,884 & $\ln ($ Diasp) & $\begin{array}{r}\ln (\text { POPi.P } \\
\text { OPj) }\end{array}$ & Ln(dist) & rel & Relig I & $\ln (\mathbf{M i j})$ \\
\hline USA & 80,000 & $329,000,000$ & 9,300 & 28,691 & 11.290 & 35.016 & 9.138 & 15.229 & 0 & 11.02244 \\
\hline Greece & 150,000 & $10,816,000$ & 1,845 & 15,404 & 11.918 & 31.601 & 7.520 & 8.176 & 1 & 11.24413 \\
\hline Ukraine & 150,000 & $42,542,000$ & 1,467 & 3,987 & 11.918 & 32.971 & 7.291 & 2.116 & 1 & 12.07271 \\
\hline Germany & 25,000 & $80,000,000$ & 2,641 & 23,521 & 10.127 & 33.602 & 7.879 & 12.485 & 0 & 10.22303 \\
\hline Cyprus & 7,000 & 500,000 & 2,629 & 17,065 & 8.854 & 28.527 & 7.874 & 9.058 & 1 & 9.373613 \\
\hline Italy & 12,000 & $59,571,000$ & 2,669 & 22,353 & 9.393 & 33.307 & 7.889 & 11.865 & 0 & 10.0437 \\
\hline Spain & 30,000 & $46,700,000$ & 4,025 & 16,258 & 10.309 & 33.064 & 8.300 & 8.630 & 0 & 9.873328 \\
\hline Belgium & 20,000 & $11,200,000$ & 3,229 & 22,405 & 9.903 & 31.636 & 8.080 & 11.892 & 0 & 9.026268 \\
\hline France & 20,000 & $66,700,000$ & 3,372 & 20,740 & 9.903 & 33.420 & 8.123 & 11.008 & 0 & 10.09997 \\
\hline UK & 15,000 & $64,100,000$ & 3,542 & 20,516 & 9.616 & 33.381 & 8.172 & 10.890 & 0 & 10.07354 \\
\hline Austria & 10,000 & $8,500,000$ & 2,339 & 23654 & 9.210 & 31.360 & 7.757 & 12.555 & 0 & 8.875542 \\
\hline Netherlands & 5,000 & $17,419,000$ & 3,203 & 23403 & 8.517 & 32.078 & 8.072 & 12.422 & 0 & 9.293949 \\
\hline Israel & 10,000 & $9,241,000$ & 1,396 & 19,892 & 9.210 & 31.444 & 7.241 & 10.558 & 0 & 8.946923 \\
\hline All & & 1607744 & & & & & & & & \\
\hline
\end{tabular}

distance between their capitals is not correct. Therefore, we removed Russia and Turkey from Table 5, which was followed by the removal of the common border column, because Georgia does not have a common border with other countries; Also, we removed the 
Table 8

\begin{tabular}{|c|c|c|c|c|c|c|c|c|}
\hline SUMMARY OUTPU & & & & & & & & \\
\hline \multicolumn{9}{|c|}{ Regression Statistics } \\
\hline Multiple R & 0.8803692 & & & & & & & \\
\hline R Square & 0.77505 & & & & & & & \\
\hline Adjusted R Square & 0.662575 & & & & & & & \\
\hline Standard Error & 0.6369501 & & & & & & & \\
\hline Observations & 13 & & & & & & & \\
\hline \multicolumn{9}{|l|}{ ANOVA } \\
\hline & $d f$ & SS & MS & $F$ & Significance $F$ & & & \\
\hline Regression & 4 & 11.18264364 & 2.795661 & 6.890864 & 0.010499028 & & & \\
\hline Residual & 8 & 3.245643271 & 0.405705 & & & & & \\
\hline \multirow[t]{2}{*}{ Total } & 12 & 14.42828691 & & & & & & \\
\hline & Coefficients & Standard Error & $t$ Stat & $P$-value & Lower 95\% & Upper 95\% & Lower $95.0 \%$ & Upper $95.0 \%$ \\
\hline Intercept & -9.713269 & 4.928701494 & -1.97076 & 0.084245 & -21.078875 & 1.6523371 & -21.07887495 & 1.652337102 \\
\hline $\ln ($ POPi.POPj) & 0.6035653 & 0.161679948 & 3.733087 & 0.005762 & 0.230730712 & 0.9764 & 0.230730712 & 0.976399971 \\
\hline $\operatorname{Ln}($ dist $)$ & -0.046002 & 0.576278413 & -0.07983 & 0.938336 & -1.3749028 & 1.282898 & -1.374902803 & 1.282898004 \\
\hline rel & 0.0014074 & 0.111500673 & 0.012622 & 0.990238 & -0.25571363 & 0.2585284 & -0.255713625 & 0.2585284 \\
\hline Relig & 2.2183987 & 0.745362854 & 2.976267 & 0.017701 & 0.499588912 & 3.9372086 & 0.499588912 & 3.937208557 \\
\hline
\end{tabular}

corresponding column of compatriots, resulting in Table 7; Using MS Excel's Data> Regression function according to Table 7 will give you the values given in Table 8 at $95 \%$ confidence intervals:

The column in this table, called "Coefficients", gives us a model of migration from Georgia obtained by regression:

$$
\ln \left(M_{i j}\right)=-9.713+0.604 \ln \left(P O P_{i} . P O P_{j}\right)-0.046 \ln (\text { dist })+0.0014 r e l
$$

Comparing the values calculated by the formula (4) of the population emigrating from Georgia to the respective countries with the data of the Ministry of Diaspora in the last column of Table 5 shows that formula (5) is not characterized by the shortcomings of formula (4). However, migration to Russia and Turkey is not calculated by this formula.

Thus, the article adopts two new models of migration from Georgia to leading European countries through formulas (4) and (5) obtained by multivariate linear regression and containing dummy variables, including a new dummy parameter "religion". It is hypothesized that migration between neighbor countries may not be analogous to the gravitational law of gravity; In our view, it would be more appropriate to use other physical assumptions to construct such a migration model, for example a mathematical model of the law of equalization of temperatures in an area with different temperatures at different points.

\section{REFERENCES}

Chakrabarti, B., Chakraborti, A. \& Chatterjee, A., (2006). Econophysics and Sociophysics. s.I.:Wiley-VCH.

Paas, T., Scannel , N. \& Tafenau, E., (2008). Gravity Equation Analysis in the Context of International Trade. Eastern European Economics, vol. 46, 92-113.

Leitao, N. The gravity model and united states trade. European Journal of Economics. Finance and Administrative Sciences, vol. 20, pp. 91-100, 2010.

Gheorghiu, A. \& Spanolescu, I., (2015). An Econophysics Model of the Migration Phenomena. Available at: http://arxiv.org/ ftp/arxiv/papers/1202/1202.0996.pdf

Molho, I., (1986). Theories of Migration: A Review. Scottish Journal of Political Economy, 33(4), 396-419.

Lewer, J. \& van den Berg, H. A (2008). Gravity Model of Immigration. Economics Letters, vol. 99, 164-167.

United Nations, N. Y., (2019). World Population Prospects. Available at: http://esa.un.org/unpd/wpp/Publications/Files/Key_ Findings_WPP_2015.pdf 
World Bank, (2019). GDP per Capita by Country. Statistics from the World Bank, 1960-2017. Available at: https://knoema. com/jesoqmb/gdp-per-capita-by-country-statistics-from-the-world-bank-1960-2017?country=Spain

Pew Research Center, (2019). Pew Research Center. Available at: https://www.pewresearch.org/

https://1tv.ge/news/amerikis-khma-yvelaze-meti-qartveli-emigranti-rusetshi-ckhovrobs/

https://opendatablog.wordpress.com/2015/05/01/sazgvargaret-mcxovrebi-qartuli-diaspora/

Pipia, K. (2015) On electrostatic models of population migration. Paata Gugushvili Institute of Economics of TSU, Current Problems of Sustainable Development of the National Economy., 99-102.

Tutberidze, G; Pipia, K; Rakviashvili, G; Kuntchulia, P. On the gravitational model of the population of Georgia (in Georgian). Globalization and Business, Volume 1, 53-59, 2016.

Tutberidze G., Pipia K., \& Kunchulia P. (2016). On Electrostatic Models of Migration. Proceedings of Scientific Works of Paata Gugushvili Institute of Economics of TSU IX, 410-414. 